\title{
A study of aerobic bacteriological profile of chronic suppurative otitis media in a tertiary care hospital, South India
}

\author{
Smitha N R ${ }^{1}$, Jnaneshwara K B ${ }^{2, *}$, Asha B Patil ${ }^{3}$, Harshika Y K ${ }^{4}$, Shobha Medegar ${ }^{5}$ \\ ${ }^{1}$ Post Graduate Student, ${ }^{\mathbf{2}}$ Assistant Professor, ${ }^{3}$ Professor and Head, ${ }^{4,5}$ Tutors, Dept. of Microbiology, Karnataka Institute of \\ Medical Sciences, Hubli, Karnataka, India \\ *Corresponding Author: Jnaneshwara K B \\ Email: jnaneshwarakb@gmail.com
}

Received: $5^{\text {th }}$ October, 2018

Accepted: $12^{\text {th }}$ October, 2018

\begin{abstract}
Introduction: In the Otolaryngology Out Patient Department (OPD), Chronic Suppurative Otitis Media (CSOM) is the most common encountered otological disease. Staphylococcus aureus and Pseudomonas species are the most commonly encountered etiological agents. Untreated CSOM leads to complications such as facial nerve paralysis, lateral sinus thrombosis, labyrinthitis, meningitis and brain abscess.

Materials and Methods: Patients with CSOM having unilateral or bilateral ear discharge for more than 3 months, attending Otolaryngology OPD or admitted in the wards were included in the study. Two swabs were collected from each patient with sterile precautions and submitted to the Microbiology Department. The samples were subjected to Gram's stain and culture according to standard operative procedure. Antibiotic susceptibility testing was performed by Kirby-Bauer's disc diffusion method as per CLSI guidelines.

Results: A total of 520 samples were collected, out of which 474 samples showed growth. Staphylococcus aureus was the predominant isolate followed by Pseudomonas species. Staphylococcus isolates were highly sensitive to vancomycin and linezolid. Conclusion: Several studies have showed the predominance of different etiological agents in different geographical regions with different antibiotic sensitivity pattern. So, the knowledge of local etiological agent and its susceptibility pattern helps clinicians in treating the patients and to prevent its complications and drug resistance.
\end{abstract}

Keywords: CSOM, Staphylococcus aureus, Pseudomonas aeruginosa, Antibiotic susceptibility pattern, Aerobic bacteria.

\section{Introduction}

Chronic Suppurative Otitis Media (CSOM) is one of the most commonly encountered diseases in the Otolaryngology practice. CSOM is a disease of multiple aetiologies and is well known for its persistence and recurrence. The World Health Organization (WHO) defines CSOM as "Otorrhoea, i.e. ear discharge through perforated tympanic membrane present for at least 2 weeks", though few guidelines takes "chronic" as symptoms persisting for more than 6 weeks. ${ }^{1}$

CSOM is classified into two types, tubotympanic and atticoantral, depending on whether the disease process affects the pars tensa or pars flaccida of the tympanic membrane (TM). ${ }^{2}$

The disease is worldwide in distribution. ${ }^{3}$ Incidence of the disease is higher in developing countries, especially among the low socioeconomic societies because of malnutrition, overcrowding, poor hygiene, inadequate health care and recurrent upper respiratory tract infections. ${ }^{4}$

CSOM, whether atticoantral or tubotympanic type is almost always associated with mixed bacterial flora. Various studies have shown both gram positive and gram negative organisms as causative agents of CSOM. ${ }^{5-7}$ Untreated CSOM leads to complications such as facial nerve paralysis, lateral sinus thrombosis, labyrinthitis, meningitis and brain abscess. ${ }^{8}$

Changes in bacterial flora causing CSOM in the last decade have been confirmed and described by many authors. ${ }^{2,3,5,6}$ So, the knowledge of the local prevalence of most common etiological agent and its antimicrobial susceptibility pattern is essential for efficacious treatment of this disease.

So, the present study was undertaken to determine the aerobic bacterial profile, most common bacterial aetiology in our geographical area and the antimicrobial susceptibility pattern of bacterial agents causing CSOM.

\section{Aims and Objectives}

1. To identify the most common aerobic bacteria responsible for causing CSOM in our geographical area.

2. To determine the antibiotic sensitivity pattern of the isolated organisms.

\section{Materials and Methods}

Study Design: The present study is a cross sectional study conducted in the department of Microbiology, Karnataka Institute of Medical Sciences, Hubli, Karnataka (India), over a period of 12 months from July 2017 to June 2018.

Inclusion Criteria: Patients of all age groups and both gender, with history of repeated ear discharge (Unilateral or Bilateral) for more than 3 months, clinically diagnosed as cases of CSOM were included in the study. Exclusion Criteria: Patients with ear discharge of less than 3 months of duration. 
1. Patients with ear discharge with intact tympanic membrane.

2. Patients receiving antibiotics at the time of presentation or within a week of presentation.

Sample Collection and Transportation: Ear discharge was collected under aseptic precautions, the external ear was cleansed with $70 \%$ ethyl alcohol to reduce the contaminating skin flora. This was allowed to dry. Then using a sterile auditory speculum, a sterile cotton swab stick was introduced into the middle ear for collecting the discharge. ${ }^{9}$ The swabs were immediately transported to the Microbiology laboratory and were processed for Gram's stain, aerobic bacterial culture and antibiotic susceptibility testing.

Sample Processing: Out of the 2 swabs, one was used for direct microscopy, and the other one for inoculating the media for aerobic bacterial culture. ${ }^{9}$

Gram's Stain: Using the first swab, a smear was made and Gram stain was performed and observed under the microscope.

Aerobic Bacterial Culture: The second swab was inoculated onto Blood agar, Chocolate agar and MacConkey agar. The inoculated media were incubated aerobically at $37^{\circ} \mathrm{C}$ for 24 hours. In case of no growth after 24 hours, the plates were further incubated for another 24 hours. If there is no growth even after 48 hours of incubation, the plates were discarded.

Organisms isolated were then identified on the basis of their colony morphology, microscopy, cultural characteristics and biochemical reactions as per the standard operating procedures. ${ }^{10}$

Antimicrobial Susceptibility Testing: The antibiotic sensitivity of aerobic bacterial isolates was performed on Mueller Hinton agar (MHA) plates by standardized Kirby - Bauer disc diffusion method as per the Clinical Laboratory Standards Institute guidelines (CLSI 2017). ${ }^{11}$

Inoculum turbidity was adjusted to $0.5 \mathrm{McFarland}$ turbidity. A lawn culture was made on the MHA plate using sterile cotton swab and appropriate antibiotic discs were applied. The plates were incubated for 18-24 hours. After 24 hours, reading was taken and zone of inhibition was read and recorded. The diameter of each zone of inhibition was measured and recorded.

The culture media and antimicrobial discs were obtained from Hi Media Laboratories Private Limited, Mumbai (India).The quality control for antimicrobial susceptibility testing was done with Escherichia coli (ATCC 25922), Staphylococcus aureus (ATCC 25923) and Pseudomonas aeruginosa (ATCC 27853).

Antibiotics Tested for Gram Positive Cocci:

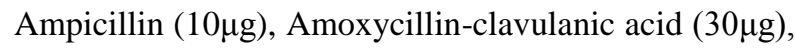
Erythromycin $(15 \mu \mathrm{g})$, Clindamycin $(2 \mu \mathrm{g})$, Ciprofloxacin $(5 \mu \mathrm{g})$, Levofloxacin $(5 \mu \mathrm{g})$, Amikacin $(30 \mu \mathrm{g})$, Gentamicin $(10 \mu \mathrm{g})$, Cefoxitin $(30 \mu \mathrm{g})$, Co-trimoxazole $(25 \mu \mathrm{g})$, Linezolid $(15 \mu \mathrm{g})$, Teicoplanin $(30 \mu \mathrm{g})$ and Vancomycin $(30 \mu \mathrm{g})$.

Antibiotics Tested for Pseudomonas Species: Amikacin $(30 \mu \mathrm{g})$, Gentamicin $(10 \mu \mathrm{g})$, Ciprofloxacin
$(5 \mu \mathrm{g})$, Levofloxacin $(5 \mu \mathrm{g})$, Piperacillin $(100 \mu \mathrm{g})$, Piperacillin-tazobactum $(100 / 10 \mu \mathrm{g}), \quad$ Ceftazidime $(30 \mu \mathrm{g})$, Cefepime $(30 \mu \mathrm{g})$, Cefoperazone $(75 \mu \mathrm{g})$, Cefpodoxime $(10 \mu \mathrm{g})$, Imipenem $(10 \mu \mathrm{g})$ and Aztreonam $(30 \mu \mathrm{g})$.

Antibiotics Tested for other Gram Negative Bacilli: Ampicillin $(10 \mu \mathrm{g})$, Amoxycillin-clavulanic acid $(30 \mu \mathrm{g})$, Ofloxacin $(5 \mu \mathrm{g})$, Levofloxacin $(5 \mu \mathrm{g})$, Amikacin $(30 \mu \mathrm{g})$, Gentamicin $(10 \mu \mathrm{g})$, Cefepime $(30 \mu \mathrm{g})$, Ceftriaxone $(30 \mu \mathrm{g})$, Cefotaxime $(30 \mu \mathrm{g})$, Ceftazidime $(30 \mu \mathrm{g})$, Cefazolin $(30 \mu \mathrm{g})$, Cefoxitin $(30 \mu \mathrm{g})$, Piperacillintazobactam $(100 / 10 \mu \mathrm{g})$, and Imipenem $(10 \mu \mathrm{g})$.

\section{Statistical Analysis}

The analysed results were expressed as percentage and proportions for the distribution of CSOM cases according to age, sex, unilateral or bilateral discharge etc.

\section{Results}

The present study included 520 patients attending the Otolaryngology OPD/admitted in wards with complaints of unilateral or bilateral ear discharge for more than 3 months. The age group of the patients ranged from 6 months to 80 years, with highest prevalence seen in 0-20 years. Declining trend was observed as the age advances (Graph 1). Out of 520 cases, 275 males and 245 females were affected.

In the current study, unilateral infection (83.07\%) of the ear was more common compared to bilateral infection (16.92\%), with the right ear being more affected than the left ear. In the present study, the disease was found to be more prevalent in rural areas than in the urban areas.

Out of 520 samples, 474 samples showed growth with isolation rate of $91.15 \%$, rest of the 46 samples were aerobically sterile. Out of 474,449 were pure bacterial isolates and 25 samples showed mixed growth. (Graph 2).

In the present study, a total of 499 aerobic bacteria were isolated, of which Staphylococcus aureus was predominant, followed by Pseudomonas species, Escherichia coli, Klebsiella pneumoniae, Citrobacter species, Prtoeus species, non fermenting gram negative bacilli and skin contaminants (Table 1). Staphylococcus aureus with Pseudomonas species was the most common polymicrobial growth pattern observed in the present study (Table 2).

S. aureus isolates were found to be $100 \%$ sensitive to vancomycin, linezolid followed by aminoglycosides, levofloxacin, co-trimoxazole and clindamycin. $28(16.27 \%)$ isolates were found to be Methicillin resistant Staphylococcus aureus, which were $100 \%$ sensitive to vancomycin and linezolid (Graph 3 ).

Pseudomonas species is the second most common organism, which is highly sensitive to aminoglycoside and imipenem followed by piperacillin and are least sensitive to ciprofloxacin and cephalosporins (Graph 4). 
Gram negative isolates showed maximum sensitivity to imipenem and aminoglycosides. They were least sensitive to penicillin, ciprofloxacin and cephalosporins (Graph 5).

\section{Graph 1: Age wise distribution of CSOM cases}

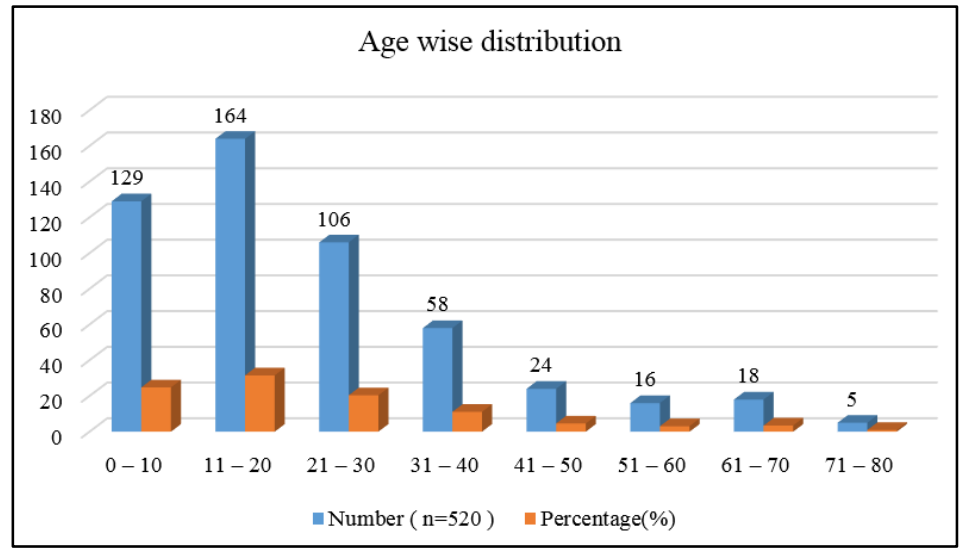

Graph 2: Growth pattern of CSOM

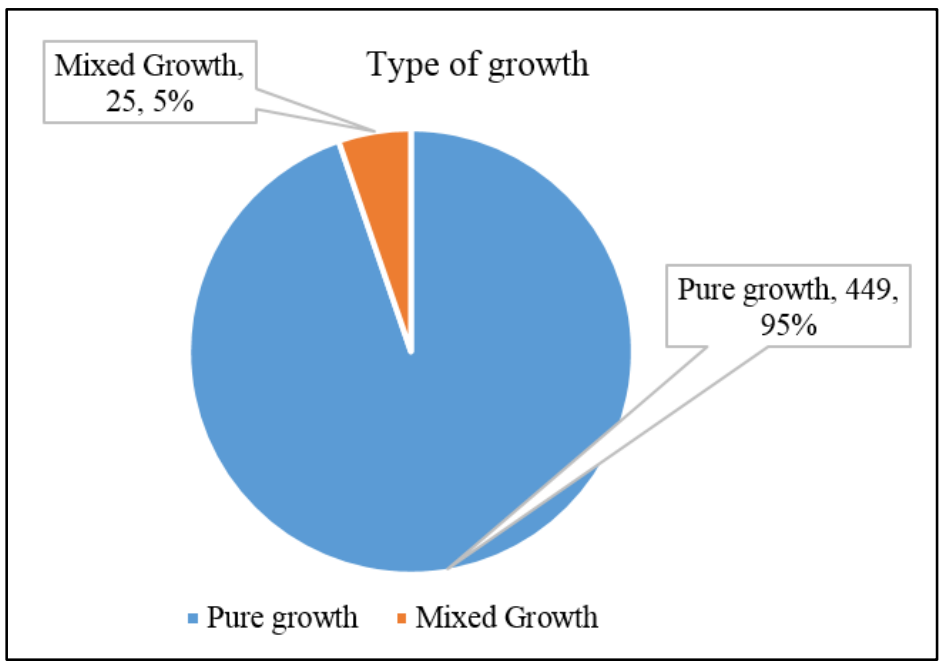

Table 1: Distribution of aerobic bacterial organisms causing CSOM

\begin{tabular}{|l|c|c|c|}
\hline S. No. & Isolate & Number & Percentage \\
\hline 1 & Staphylococcus aureus & 172 & $34.46 \%$ \\
\hline 2 & Pseudomonas species & 148 & $29.65 \%$ \\
\hline 3 & Escherichia coli & 80 & $16.03 \%$ \\
\hline 4 & Klebsiella species & 45 & $9.01 \%$ \\
\hline 5 & Citrobacter species & 20 & $4.00 \%$ \\
\hline 6 & Proteus species & 14 & $2.33 \%$ \\
\hline 7 & Non Fermenting Gram Negative Bacilli & 10 & $2.00 \%$ \\
\hline 8 & Skin contaminants & 10 & $2.00 \%$ \\
\hline \multicolumn{2}{|c|}{ Total } & 499 & 100 \\
\hline
\end{tabular}

Table 2: Distribution of polymicrobial growth pattern in CSOM

\begin{tabular}{|l|c|c|}
\hline S. No. & Mixed isolates & Number \\
\hline 1 & Staphylococcus aureus + Pseudomonas species & 12 \\
\hline 2 & Staphylococcus aureus + Escherichia coli & 4 \\
\hline 3 & Staphylococcus aureus + Klebsiella species & 3 \\
\hline 4 & Pseudomonas species + Escherichia coli & 4 \\
\hline 5 & Escherichia coli + Proteus species & 2 \\
\hline
\end{tabular}


Graph 3: Antibiotic resistance pattern in Staphylococcus aureus

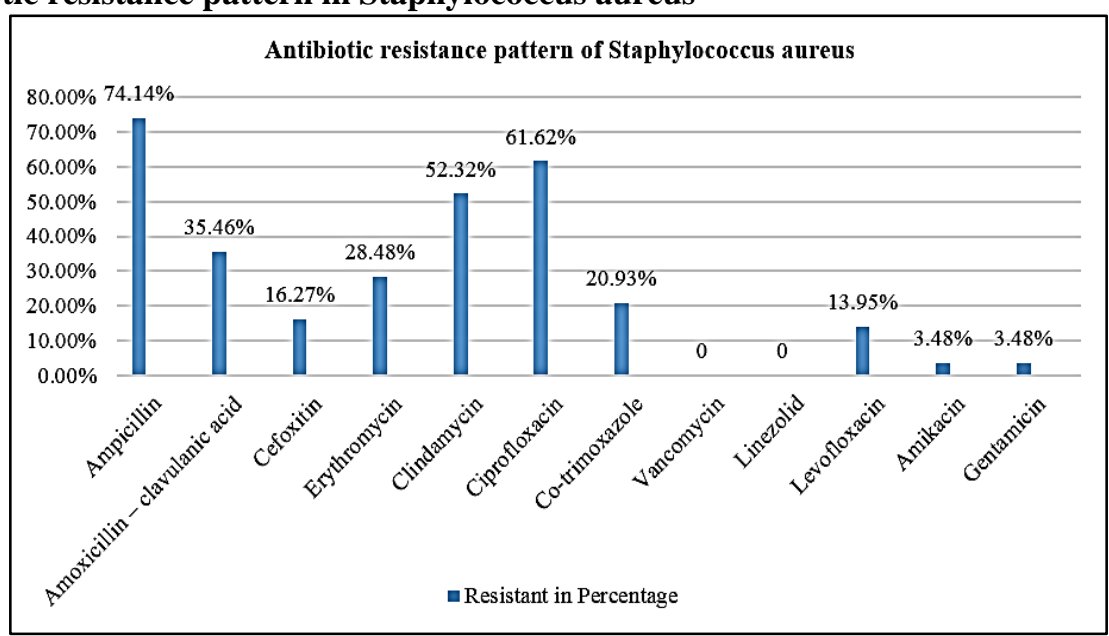

Graph 4: Antibiotic resistance pattern in Pseudomonas species

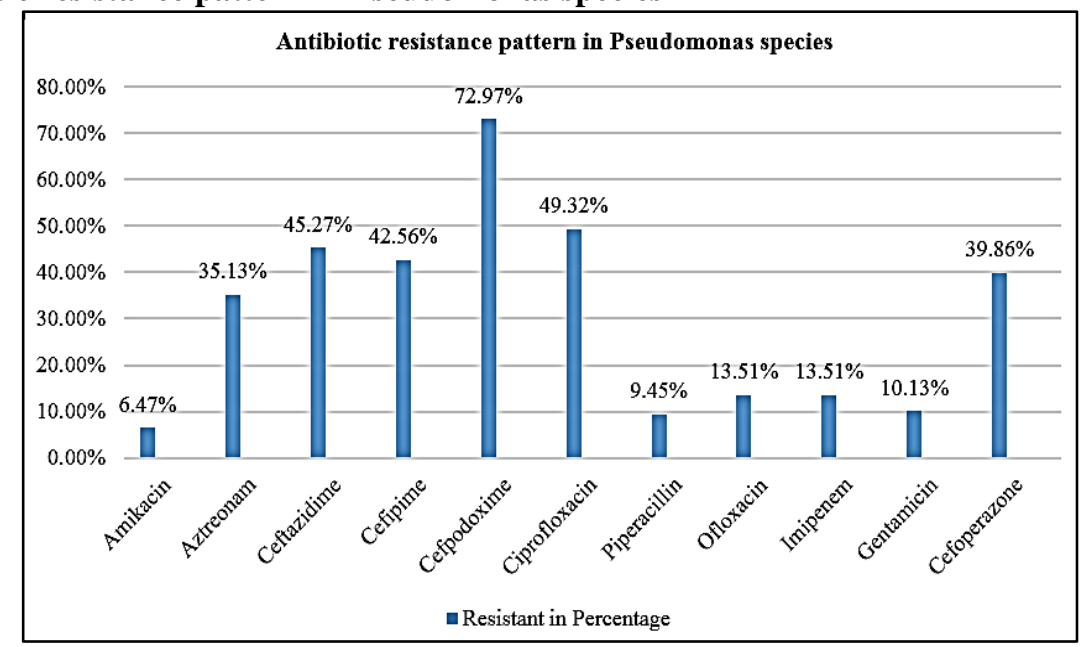

Graph 5: Antibiotic resistance pattern in gram negative bacilli

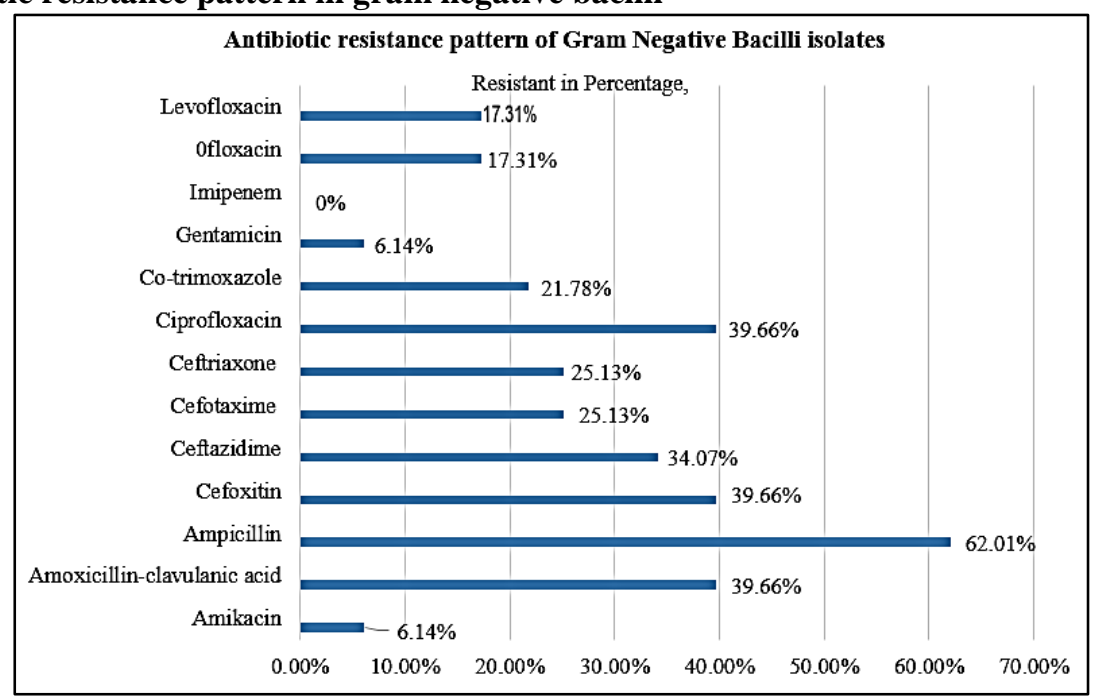

\section{Discussion}

CSOM is a major public-health problem, and India is one of the countries with high-prevalence where urgent attention is needed. ${ }^{12}$ WHO has classified the countries into different groups according to the prevalence of CSOM as highest (> 4\%), high $(2-4 \%)$, 
low $(1-2 \%)$, and lowest $(<1 \%)$, in which India comes under highest category (WHO, 1998). Prevalence of CSOM in India according to the WHO reports is $7.8 \%$ which puts India amongst the group with the highest prevalence and hence demands immediate attention to deal with a massive public health problem. ${ }^{13}$

The gram positive (Staphylococcus aureus, Streptococcus pneumoniae) and gram negative (Pseudomonas aeruginosa, Escherichia coli, Proteus species, Klebsiella species) bacteria are involved in the pathogenesis of CSOM. ${ }^{14}$

CSOM is an important cause of preventable hearing loss and is of serious concern in paediatric age group because it may have long-term effects on early communication, language development, educational process, auditory processing and physiological and cognitive development. ${ }^{15}$

Pseudomonas is the predominant cause of CSOM in tropical region and does not usually inhabit the upper respiratory tract. It's presence in the middle ear cannot be ascribed to an invasion through Eustachian tube (ET) and it should be considered as a secondary invader gaining access to the middle ear through defect in TM. ${ }^{16}$

Poor hygiene and unorthodox approach to treatment like use of unconventional ear drops and concoctions such as oil and honey into the middle ear should be avoided. $^{17}$

Early microbiological diagnosis ensures prompt and effective treatment to avoid such complications. The mainstay of treatment for uncomplicated CSOM is twofold: meticulous aural toilet and instillation of a topical and systemic antimicrobial agent. The therapeutic use of antibiotics is usually started empirically prior to results of microbiological culture. Selection of any antibiotic is influenced by its efficacy, resistance of bacteria, safety, risk of toxicity and cost. Knowledge of the local microorganism pattern and their antibiotic sensitivity is thus essential to allow for effective and cost-saving treatment.

Microbiology cultures yield many, frequently multiple organisms and these vary depending on climate, patient population and whether antibiotics have or have not been recently used. Several studies have reported different organisms in different proportions. ${ }^{18}$

In the present study, among the total cases, 275 males and 245 females were affected with male to female ratio of 1.12:1, which is similar to study done by Prakash $\mathrm{R}^{5}$ et al., however Teele ${ }^{19}$ et al., have found female preponderance.

In the current study, increased occurrence of unilateral ear $(83 \%)$ was observed with least occurrence in bilateral ear $(16.9 \%)$ among CSOM patients, which is in accordance with a study by Nwokoye ${ }^{16}$ et al.

In this study, Staphylococcus aureus is the most common isolate, followed by Pseudomonas species, which is in agreement with Prakash $\mathrm{M}^{6}$ et al., and Ahmed S. Shyamala $\mathrm{R}^{7}$ et al. and several other studies have shown that Pseudomonas is the most common organism.
In this study, S. aureus isolates showed alarming resistance to ciprofloxacin, which could be due to irrational use, inadequate dosage and also its availability over the counter. In contrast, least resistance was seen to aminoglycosides. 28 isolates were found to be methicillin resistant Staphylococcus aureus, which are $100 \%$ sensitive to vancomycin and linezolid.

Sensitivity of Pseudomonas species to imipenem and aminoglycosides is maximum $(93.52 \%)$ followed by piperacillin $(90.64 \%)$ and these are least sensitive to ciprofloxacin and cephalosporins and these are in accordance with the study done by Harshika $\mathrm{YK}^{20}$ et al.

In our study, gram negative bacilli showed maximum sensitivity to carbapenems and amikacin. Maximum resistance to ampicillin and cephalosporin. These are in agreement to the study done by Harshika $\mathrm{YK}^{20}$ et al.

Aminoglycosides show least resistance to gram negative bacilli including Pseudomonas species, probably because they are not commonly used, as they are ototoxic.

The frequency of Staphylococcus aureus in the middle ear infections can be attributed to their ubiquitous nature and high carriage of resistant strains in the external auditory canal and upper respiratory tract. The organisms like Pseudomonas species and Proteus species are considered mostly as secondary invaders from external auditory canal giving access to the middle ear via defect in tympanic membrane resulting from an acute episode of otitis media. Organisms like E.coli and Klebsiella spp. become opportunistic pathogens in the middle ear when the resistance is low.

Above studies showed that, the microbial profile vary between different regions geographical distribution and based on patient population. So, it urges the need for frequent analysis and update of the microbial profile in every geographical region.

\section{Limitations of this Study}

In this study, 46 samples were aerobically sterile, which may be due to either anaerobic or fungal aetiology, or prior antibiotic therapy. Hence further studies are encouraged to overcome these limitations.

\section{Conclusion}

Knowing the etiological agents of CSOM and their antibiogram is of paramount importance for an efficient treatment and prevention of both disease complications and antimicrobial resistance. In the present study Staphylococcus aureus is the most common etiologic agent of CSOM followed by Pseudomonas species. Proper selection of topical/systemic antibiotics guided by culture and sensitivity report with keeping ear dry is the effective treatment modality of CSOM to prevent drug resistance, unwanted antibiotic administration and complications. 


\section{References}

1. WHO, Report by the Director General. Prevention of Deafness and Hearing Impairment. Document A39/14, World Health Organization, Geneva, 1986.

2. Kumar H, Seth S. Bacterial and fungal study of 100 cases of chronic suppurative otitis media. J Clin Diagn Res. 2011;5:1224-7.

3. Rout MR, Mohanty D, Vijaylaxmi Y, Kamalesh B, Chakradhar M. Prevalence of cholesteatoma in chronic suppurative otitis media with central perforation. Indian $J$ Otol. 2012;18:7-10.

4. Poorey VK, Thakur P. Clinicomicrobiological evaluation and antibiotic susceptibility in cases of chronic suppurative otitis media. Indian J Otol. 2015;21:107-10.

5. Prakash R, Juyal D, Negi V, Pal S, Adekhandi S, Sharma $\mathrm{M}$, et al. Microbiology of chronic suppurative otitis media in a tertiary care setup of Uttarakhand state, India. $N \mathrm{Am} \mathrm{J}$ Med Sci. 2013;5:282-7.

6. Prakash M, Lakshmi K, Anuradha S, Swathi GN. Bacteriological profile and their antibiotic susceptibility pattern of cases of CSOM. Asian J Pharm Clin Res. 2013;6:210-2.

7. Shyamala R, Reddy PS. The study of bacteriological agents of chronic suppurative otitis media: Aerobic culture and evaluation. J Microbiol Biotech Res. 2012;2:152-62.

8. Shenoi P. Management of chronic suppurative otitis media. In: Scott-Brown's Otolaryngology, 6th ed. Oxford, London, Boston, Butterworth-Heinemann, 1987:215-23.

9. Koneman EW, Allen SD, Janda WM, Schreckenberger PC, Winn WC. Color Atlas and text book of Diagnostic Microbiology, Philadelphia, Lippincott, New York, 1997; 5th edition, 1296-1395.

10. Collee JG, Duguid JP, Fraser AG, Marmion BP, editors. Edinburgh: Churchill Livingstone; Mackie and McCartney's Practical Medical Microbiology; 14th edition; 1996:60-1.

11. Clinical and Laboratory Standards Institute. Performance standards for antimicrobial susceptibility testing. 27th Informational Supplement. CLSI document M100-S27. Wayne, PA; 2017.
12. Sabarinathan TV, Rajkumari A. Bacteriological and Resistance Profile in Isolates of Chronic Suppurative Otitis Media. Int J Biol Med Res. 2015;6(3):5216-8.

13. Sharma K, Oberoi L, Narula V. Present scenario of microbiological pattern in chronic suppurative otitis media and its management guidelines. J Acad Cli Microb. 2017;19(1):47-53.

14. Khatoon A, Rizvi M, Sultan A, Khan F, Sharma M, Shukla I, et.al. Chronic suppurative otitis media: a clinicmicrobiological menance. International. J Res Med Sci. 2015;3(8):1932-36.

15. Mukherjee P, Saunders N, Liu R, Fagan P. Long term outcome of modified radical mastoidectomy. J Laryngol Otol. 2004; 118:612-6.

16. Vishwanath S, Mukhopadhyay C, Prakash R, Pillai S, Pujary K, Pujary P. Chronic suppurative otitis media: Optimizing initial antibiotic therapy in a tertiary care setup. Indian J Otolaryngol Head Neck Surg. 2012;64:285-9.

17. Nwokoye NN, Egwari LO, Coker AO, Olubi OO, Ugoji EO, Nwachukwu SC. Predisposing and bacteriological features of otitis media. Afr J Microbiol Res. 2012;6:5205.

18. Sweeney G, Piccozi GL, Browning GG. A quantitative study of aerobic and anaerobic bacteria in chronic suppurative otitis media. J Infect. 1982;5:47-55.

19. Teele, D.W., Klein, J.O., Rosner, B. Greater Boston Otitis Media Study Group. Epidemiology of otitis media during the first seven years of life in children in greater Boston: A prospective, cohort study. J Infect Dis. 1989;160:8394.

20. Harshika YK, Sangeetha S, Prakash R. Microbiological profile of CSOM and their antibiotic sensitivity pattern in a tertiary care hospital. Int J Curr Microbiol App Sci. 2015;4(12):735-743.

How to cite this article: Smitha $\mathrm{N} R$, Jnaneshwara $\mathrm{K}$ B, Patil A.B, Harshika Y K, Medegar S. A study of aerobic bacteriological profile of chronic suppurative otitis media in a tertiary care hospital, South India. Indian J Microbiol Res. 2018;5(4):470-475. 